\title{
GENEALOGICAL ANNOTATION IN GENESIS AS BACKGROUND FOR THE MATTHEAN GENEALOGY OF JESUS
}

\author{
John Nolland
}

\begin{abstract}
Summary
The Matthean genealogy can helpfully be classified as an annotated genealogy, a type of genealogy which is notable in Genesis. Annotation and other forms of breach of standard patterns in the Genesis genealogies function particularly to set genealogies into their wider narrative context and to ensure that the genealogies function as compressed tellings of the history that stands behind them. It is likely that Matthew learned his craft for the creation of an annotated genealogy from study of the genealogical material in Genesis.
\end{abstract}

Quite apart from the framing information provided in Matthew 1:1 and 17, the simple father-son sequence of the Matthean

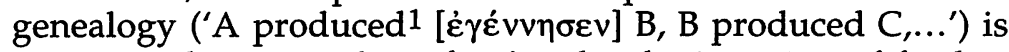
interrupted at a number of points by the insertion of further information of one kind or another. For example, we learn that 'Jacob produced Judah and his brothers' (v. 2; cf. v. 11); we are given the names (or other identifying description) of the mothers on five occasions (vv. 3, 5, 6, 16); the Babylonian exile is mentioned in vv. 11 and 12; and Jesus is further identified in v. 16 as 'who is called Christ'. Another kind of disturbance to the regular pattern is also found at the end of the genealogy ( $\mathrm{v}$. 16), where, in connection with the origins of Jesus, the passive of the verb referring to reproduction is used: 'Jesus was produced ( $\dot{\varepsilon} \gamma \varepsilon v v \eta \dot{\theta} \theta)$. $^{\prime}$ Other more subtle disturbances can be

\footnotetext{
1I have chosen to render $\gamma \varepsilon v v \alpha$ ' $\omega$ 'produce' in Matthew to allow for a consistent representation of the relationship between the male and female role in Matthew 1. Where possible I have carried this convention over to the Genesis text (Heb. ילד).
} 
identified by comparing the Matthean list with the pertinent Old Testament genealogical information. ${ }^{2}$

The genealogy is a much studied section of Matthew, 3 and each of the features identified above has been commented upon in the scholarship with varying degrees of helpfulness. But what seems to be lacking is a recognition that the annotations constitute a feature of the genealogy which deserves attention in its own right. The references to the women have regularly been studied as a set, but they have not, so far as I have been able to discover, been placed in relation to other forms of annotation in the genealogy. The role of the present study is to suggest that, having recognised that the Matthean genealogy can be helpfully classified as an annotated genealogy, a useful perspective can be established for further investigation of the genealogy by examining the role of annotation in the genealogies in Genesis. Indeed it seems likely that Matthew has learned his craft for the creation of an annotated genealogy from the genealogical material he was able to examine in Genesis.

Genealogical material in the Old Testament is concentrated in Genesis and 1 Chronicles 1-9. The other scattered genealogical material consists mostly of 'brief lists or allusions to parentage that serve mainly to identify an individual in a narrative or the author of a prophetic book.' 4

2Jechoniah is not son of Josiah as v. 11 seems to suggest. Three generations of kings are missing from $\mathrm{v} .8$.

${ }^{3}$ Besides the commentaries and other broader studies, recent studies include: C.L. Blomberg, 'The Liberation of Illegitimacy: Women and Rulers in Matthew 1-2', BTB 21 (1991) 145-150; R.E. Brown, The Birth of the Messiah (New York: Doubleday, 1993) 57-92; J.P. Heil, 'The Narrative Roles of Women in Matthew's Genealogy', Bib 72 (1991) 538-545; H. Hempelmann, 'Das "Dürre Blatt im Heiligen Buch"; Mt. 1,1-17 und der Kampf wider die Erniedrigung Gottes', TB 21 (1990) 6-23; F.J. Moloney, 'Beginning the Gospel of Matthew: Reading Matthew 1:1-2:23', Salesianum 54 (1992) 341-359; B.B. Scott, 'The Birth of the Reader', Semeia 52 (1990) 83-102; idem., 'The Birth of the Reader in Matthew: Matthew 1:1-4:16', in J.T. Carroll, et al. (eds.), Faith and History (Scholars Press Homage Series; Atlanta: Scholars, 1990) 35-54; E.M. Wainwright, Towards a Feminist Critical Reading of the Gospel according to Matthew (Berlin/New York: de Gruyter, 1991) 61-69, 156-76.

${ }^{4}$ M.D. Johnson, The Purpose of the Biblical Genealogies: With Special Reference to the Setting of the Genealogies of Jesus (SNTSMS 8; 2nd ed.; Cambridge: CUP, 1988) 3 . 
Since Matthew's genealogy begins with figures who appear in Genesis, and the opening words of its introduction ( $\beta i \beta \lambda o s$ $\gamma \varepsilon v \varepsilon \dot{\sigma \varepsilon \omega \varsigma}$ ) echo words from Genesis $2: 4 ; 5: 1,5$ it is the Genesis genealogies which have particular claim to attention. 6

A brief survey of the Genesis genealogies 7 with particular attention to the annotations will reveal a number of features in common with Matthew 1 . We will see the wide use of annotation in which the author departs from an otherwise fixed pattern for some particular reason. Very rarely will we find anything which could be considered only a careless departure from a pattern. A common feature to be observed is the use of variation from the otherwise fixed pattern to fit the genealogy into the wider literary context. But perhaps the most important of the common features to be noted is the role of the annotations in ensuring that the genealogies function as compressed tellings of the history that stands behind each. This function of genealogies is widely recognised, but the specific role of annotation in establishing this function (though perhaps self-evident at one level) has not come into focus.

Genesis 4:17-18 contains the first of the Genesis genealogies. ${ }^{8}$ Its role is to provide a bridge from the generation

${ }^{5}$ On this see J. Nolland, 'What Kind of Genesis Do We Have in Matt. 1:1?' NTS forthcoming.

${ }^{6}$ Matthew's starting point in $\mathrm{Ru}$. 4:18-21 has no annotation. His other probable source, 1 Ch. 3:10-19, is annotated, but none of its annotations have found their way into the Matthean genealogy (one could argue, however, for influence from the annotation technique: note the mention of multiple sons [by name, unlike Matthew] of Josiah in v. 15 and of Jehoiachin in v. 17, and the designation of Jehoiachin as 'the captive' in v. 17). The present restriction of attention to Genesis is not because some of the same perspectives would not emerge from consideration of genealogical materials in 1 Chronicles 1-9. The Chronicles material, however, as a single composite whole which is considerably less stable in form than the individual Genesis genealogies, has rather less in common with the Matthean genealogy.

7Since Matthew is generally considered to have had access to both Hebrew and Greek forms of the Old Testament, both the MT and LXX forms of text will be kept in view.

8It is a moot point whether we should classify vv. 19-22 as part of the genealogy, but on the basis of the end-point interest in Lamech (v. 23) I exclude these verses. If we were to include them, the mention of the names of Lamech's two wives and of the sister of Tubal-cain by name would be especially notable. We should note that both Gn. 4:1-24 and Gn. 
of Cain to that of Lamech, a descendant of Cain who asserts a scale of vengeance for himself which is eleven-fold that provided for Cain (vv. 23-24). We note at once that the fixed

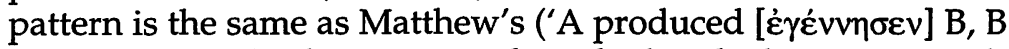
produced $C, \ldots$... The pattern is breached at the beginning with 'knew his wife, and she conceived and bore'. 9 The words echo the language of v. 1, and so place this and presumably all the following conceptions in the line of the very first human conception. Then there is the addition, still in v. 17, of 'and he built a city, and named it Enoch after his son Enoch.' This is likely to serve to distinguish him, by means of the attached activity, from the Enoch of Seth's line, who was honoured in quite a different way, but it also points up the compressedtelling-of-history aspect of the genealogy. In v. 18 there is an anomalous use of a passive construction in connection with the production of the Enoch's child ('to Enoch was born'10 instead of 'Enoch produced'). This is probably a bridging form between the identified role for the wife in v. 17 and the invisibility of the female role in the rest of v. 18. Though the idiom is not identical, the unexpected passive construction of the verb here may well have prepared the way for that in Matthew 1:16.

The second genealogy is in Genesis 5:3-32, which takes us from Adam to Noah. Again there is a fixed pattern, this time much more complicated than Matthew's ('A lived X years and produced B. A lived $Y$ years after producing $B$ and produced [other] sons and daughters'), but it contains at its core the pattern adopted by Matthew. Here the fixed genealogical pattern is breached in v. 3 by '[a son] in his likeness, according to his image, and named him'. 'In his likeness, according to his image' provides a link to v. 2 and 1:26, in order to establish the transmission of the image of God from generation to generation. 'A son' (if we should read it here) and 'named him' echo the language of 4:25, where they are linked with Eve's

5:1-32 provide 'genealogies' (one through the line of Cain and one through the line of Seth) which run from Adam to Lamech in the one case and from Adam to Lamach's son Noah in the other (different Lamechs), with some difficulty about whether to include the following generation. Each includes an Enoch who is especially emphasised, and puts special emphasis on Lamech.

${ }^{9}$ Translations are normally NRSV, but with adjustment where necessary. ${ }^{10}$ English idiom hardly allows the passive use of $\left.\gamma \varepsilon v v a ́ \omega\right)$ (ויולד) here to be rendered 'produced' (cf. note 1). 
role, and thus provide a gender balanced parallelism.11 'The days of' instead of 'lived' in v. 4 has no evident function (nor the additional 'which he lived' in v. 5) and could be considered a careless departure from the pattern. 'Walked with God' instead of 'lived' in v. 22 marks Enoch distinctively and prepares for the unique outcome of his life, which is indicated by the next breach of pattern, 'Enoch walked with God; then he was no more, because God took him', in v. 24. By marking a high point, these last breaches of pattern underscore the narrative unfolding of the time encompassed by the genealogy. 'A son; he named him' in vv. 28-29 echo the language of v. 3. If this is to enable the last generation statement of the genealogy to echo the first (which seems likely), then we would need to conclude that v. 32 was not an original part of the present genealogy.12 The phase in v. 29, ('saying, "Out of the ground that the LORD has cursed this one shall bring us relief from our work and from the toil of our hands"') makes Noah (probably the original terminus of the genealogy) a figure of hope, and creates an expectation of a narrative relating the realisation of this hope. In the present form of the genealogy, there is finally the extra sons 'Ham, and Japheth' in v. 32. The mention of all three sons prepares for their significance as ancestors of all humankind in 9:18-19. Departure from the pattern to provide links with the wider context is the dominant note in the annotations of this genealogy.

The next genealogy in Genesis (10:1-32) is a branching genealogy which moves out from Noah in the direction of the multiplication of the nations. As a branching genealogy, it is less useful for comparison with Matthew 1,13 and it is in any

${ }^{11}$ 'A son' is not found in the LXX and is only conjectural for the Hebrew text, but the role of the link with 4:25 may be offered as an additional argument in favour of such a conjecture.

12Apart from the age, the information of v. 32 could be drawn forward from 6:10. The form is significantly anomalous: 'Noah was' instead of 'Noah [had] lived'; repetition of the name 'Noah'; listing of three sons, rather than simply of the first-born (which fits ill with the initial age statement of the pattern); lack of any statement about other sons and daughters (this last could be only a by-product of the necessary lack at this point in the story [given the narrative to follow] of the details which would complete the skeleton of Noah's life).

${ }^{13} \mathrm{Gn} .10: 1-32$ is the Genesis genealogy which has the greatest affinity with (parts of) the 1 Chronicles genealogical material. 
case a less highly structured genealogy.14 Next comes a genealogy of Shem (Gn. 11:10-26) which picks up on the pattern of the Genesis 5 genealogy (except for an inversion of word order at the beginning between verb and subject, the basic pattern is identical). The first minor breach of pattern is 'was' (Heb. ב ) rather than '[had] lived' in 11:10. It is likely to be significant that this is how Noah, his father, was introduced in 5:32. 'Two years after the flood' in 11:10 also links this genealogy into the Noah materials which precede. All then unfolds according to formula until v. 26, where three sons of Terah are listed and the rest of the pattern is not completed (this is very like the situation in 5:32). The following narrative will deal with all three sons, and has a continuing place for Terah as well (cf. the situation in 5:32). ${ }^{15}$ The role of annotation and breach of pattern is the same as that for the Genesis 5 genealogy.

A branching genealogy of Esau's descendants is supplied in 36:9-43, which has some similarities with the genealogy of chapter 10.16 This genealogy is notable for the prominent role played by women, mostly in terms of sons born of different wives (or concubines), but also with the mention of Lotan's sister by name and of Oholibamah daughter of Anah. For Hadar at the end of the list of kings, we have his wife's name, but also her mother's name and her grandmother's name. The role of women is the point of obvious similarity with Matthew's genealogy.

The final 'genealogy' in Genesis is not strictly genealogy, but a list in 46:8-27 of the descendants of Jacob who descended into Egypt with him. It is mostly a list of the children of each of the twelve patriarchs. Reuben is identified in v. 8 as 'Jacob's firstborn'. For Simeon, it mentions (v. 10) that the children were 'the sons of a Canaanite woman'. An aside

${ }^{14}$ We can note, however, the annotations on Nimrod (vv. 8-12), Caphtorim (v. 14), the spread of the Canaanites (v. 18), Shem (v. 21), and Peleg (v. 25). 15Interestingly Terah's death is reported in v. 32 in terms which follow closely the form of the part of the pattern in 5:3-32 not taken up in 11:10-26 ('all' is missing from the beginning and 'in Haran' has been added at the end).

${ }^{16}$ Note annotations in vv. 9, 21, 24. From v. 31 the genealogy becomes, instead, a list of kings (unrelated to one another), which is provided with an introduction in v. 31 and has a further notable annotation in v. 35. 
indicates that 'Er and Onan died in the land of Canaan.' We are taken on to the next generation in vv. 12 and 17. After dealing with Reuben to Zebulun the text informs us in v. 15 that 'these are the sons of Leah, whom she bore to Jacob in Paddan-Aram, together with his daughter Dinah; all his sons and his daughters numbered thirty-three' and there is a similar note about Zilpah in v. 18, Rachel in v. 22 and Bilhah in v. 25. Rachel also appears in v. 19 'The children of Jacob's wife Rachel: Joseph and Benjamin.' Finally with Joseph in v. 20 we have 'in the land of Egypt' and 'whom Asenath daughter of Potiphera, priest of On, bore to him.' It is evident that Genesis 46:8-27 provides a kind of digest, and in that sense a retelling, of at least important aspects of Genesis 28-41.

It is clear, then, that the Genesis genealogies manifest a commitment similar to that found in Matthew to the basic use of a fixed pattern to express the sequence of generations. They also share a considerable incidence of breaches of the pattern (either by annotation or by change of form), but in almost every case in Genesis a likely reason can be offered for the violation of pattern. The two most important reasons for violation are a concern to fit the genealogy into the wider literary context (mostly change of form in this case) and a desire to enhance the capacity of the genealogies to function as compressed tellings of the history that stands behind them (in some cases a history to which we have no other access-here annotation comes into its own).

Particular genealogies take us a little further in identifying ways in which Matthew may have been influenced by the genealogical technique in Genesis. The role of the woman has some visibility in Genesis 4:17-18, plays an indirect role in the formation of 5:3, and comes into some prominence in Genesis 39:9-43 and 46:8-27. Mostly it is a matter of multiple wives, but Joseph's wife is named ('Asenath daughter of Potiphera, priest of $\mathrm{On}^{\prime}$ ) because of her capacity to evoke the honoured position of Joseph in Egypt, and Dinah is named because of the attention devoted to her in Genesis 34. The reasons are no longer accessible to us for the mention of Lotan's sister by name and of Oholibamah as daughter of Anah, nor for the inclusion in the case of king Hadar of not only his wife's name, but also her mother's name and her grandmother's name, but it is likely that these inclusions evoke features of a 
history which is no longer accessible to us. To Matthew's use of the time of the Deportation we can compare the note about Peleg in 10:25 'for in his days the earth was divided'; and the time note in 11:10 'two years after the flood'; as well as the chronology implied in 46:15 by 'the sons of Leah, whom she bore to Jacob in Paddan-Aram.' The mention of three sons in 5:32 and 11:26 may be compared with Matthew's mention of extra siblings in 1:2, 3, 11.17

The role of annotation and other form of breaches of pattern in the Genesis genealogies has been explored in order to compare the technique to that of the Matthean genealogy. A considerable number of shared techniques and features have been identified. Given the link to Genesis marked in Matthew 1:1 and the evident similarities between the Matthean and Genesis genealogies (similarities which are nowhere else similarly clustered in the Old Testament), it seems reasonable to suggest that, in relation to annotation of bibliographies and other forms of disturbance of the otherwise fixed pattern, Matthew learned important elements of his craft from the genealogical material in Genesis.

${ }^{17}$ More remotely the counting in Genesis 46 may be compared to the role of the fourteens in Matthew's genealogy. 